\title{
CRITICAL CARE FELLOWSHIP \\ Sunnybrook Health Science Centre \\ University of Toronto
}

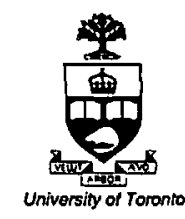

The Department of Anaesthesia at Sunnybrook Health Science Centre in Toronto, Ontario, Canada, is offering a one-year clinical fellowship in critical care medicine starting in July 1999. Sunnybrook is a Level One trauma referral centre for metropolitan Toronto and Central Ontario. The Critical Care service at our institution is a multidisciplinary team providing primary patient care to a total of 34 beds in closed cardiovascular and medical-surgical intensive care areas. These areas are the only ones in the hospital which provide positive pressure ventilation to admitted intubated patients.

The medical-surgical intensive care area admits approximately 1000 patients annually. These patients are divided equally between the trauma, medical and surgical populations. The medical-surgical team also provides daily consultant care in airway and respiratory management to a neurosurgical stepdown unit. The cardiovascular intensive care unit admits approximately 1200 postoperative cardiac and major vascular surgery patients annually.

In addition to graded experience in supervising a critical care team, this fellowship offers the opportunity for protected elective time in a variety of areas including airway management, critical care research, education, trauma resuscitation, or transesophageal echocardiography. The fellowship may also be eligible for inclusion as part of a 2-year training program accredited by the Royal College of Physicians and Surgeons of Canada.

Candidates must be eligible for RCPSC certification, American Board eligible, or hold equivalent national certification in Anaesthesia, Internal Medicine or Surgery and be eligible for licensure in the province of Ontario.

For further information, please contact:

\author{
Dr. Cameron Guest \\ Department of Anaesthesia, M3-200 \\ Sunnybrook Health Science Centre \\ 2075 Bayview Avenue \\ Toronto, Ontario \\ Canada M4N 3M5
}

\section{LOCUM AND CLINICAL FELLOWSHIP POSITIONS DALHOUSIE UNIVERSITY QUEEN ELIZABETH II HEALTH SCIENCES CENTRE}

Dalhousie University and the Queen Elizabeth II Health Sciences Centre are seeking qualified anaesthetists to join the Department of Anaesthesia. He/she should possess Certification by the Royal College of Physicians and Surgeons of Canada or International equivalent.

Halifax, the capital city of Nova Scotia, has excellent educational and recreational facilities.

Dalhousie University is an Employment Equity/Affirmative Action Employer. The University encourages applications from qualified aboriginal peoples, persons with disabilities, racially visible persons and women. In accordance with Canadian immigration requirements, this advertisement is directed to Canadian citizens and permanent residents.

Please send applications with an up-to-date curriculum vitae and the names of three referees to:

Dr. T.J. Coonan

Queen Elizabeth II Health Sciences Centre

Victoria General Hospital Site, 1278 Tower Road

Halifax, Nova Scotia B3H 2 Y9 